\title{
An Evidence-Based Evaluation of Prevailing Learning Theories on Mentoring in Palliative Medicine
}

\author{
Cheng Teng Yeam ${ }^{1 *}$, Loo Teck Wee Wesley², Ee Hui Fang Margaret ${ }^{1}$, Ravindran Kanesvaran ${ }^{3}$, Lalit Krishna ${ }^{4}$ \\ ${ }^{1}$ National Cancer Center Singapore; National University of Singapore \\ ${ }^{2}$ National Cancer Center Singapore; Yong Loo Lin School of Medicine \\ ${ }^{3}$ National Cancer Center Singapore; Duke NUS Medical School \\ ${ }^{4}$ National Cancer Center Singapore; Duke NUS Medical School; Centre for Biomedical Ethics, National University of Singapore
}

Received: November 16, 2016; Accepted: November 23, 2016; Published: December 06, 2016

*Corresponding author: Cheng Teng Yeam, National Cancer Centre Singapore; National University of Singapore, Address 11 Hospital Drive, Singapore 169610.E-mail: yeamct@u.nus.edu

\begin{abstract}
Mentoring has an essential role in Palliative Medicine education. However, extent literature in mentoring in medicine and a lack of studies into mentoring in Palliative Medicine highlights a disconnect between theory and practice. Thematic analysis of systematic reviews of mentoring in medicine between 2000 and 2015reveals common threads in prevailing mentoring approach which provide a basis for evaluation of prevailing learning theories of mentoring.

This evidence-based review, however, reveals significant gaps in prevailing data on the various aspects of the mentoring practice. These findings underline the impact of a dearth of mentoring data upon advancing a practical learning theory of mentoring essential to efforts to improve and expand Palliative Medicine mentoring programs. Nonetheless, the lack of data on the dynamics and quality of mentoring relationships, understanding of the impact of organizational factors and mentee-and mentor- dependent factors upon the mentoring process and the manner that mentoring relationships evolve serve as an area for closer attention in mentoring practice and a guide to future research.
\end{abstract}

Keywords: Palliative Medicine; Learning theory; Mentoring; Multiprofessional; Mentor; Mentee

\section{Introduction}

Palliative Medicine's evolving multidimensional nature and accent upon maximising comfort and quality of life that "requires changing one's conceptual model from disease and diagnosis to patient goals, prognosis and function" creates a unique challenge for medical educators and curriculum planners [1]. Mentoring has been proposed as a means of circumnavigating Palliative Medicine's educational hurdles [2-5]. Though theoretically viable, the employment of mentoring in Palliative Medicine has been hindered by the presence of a variety of descriptions of mentoring approaches and practices. The situation is compounded by an absence of a clear definition of mentoring and a lack of a clear understanding of mentoring approaches have slowed the development of effective mentoring programs [6-8].

Whilst reviews of mentoring in medicine have sought to characterize and define mentoring practice, a lack of viable learning theories in mentoring represent a considerable obstacle to mentoring in medicine in general and indeed in Palliative Medicine [3, 9-20]. A learning theory of mentoring in Palliative Medicine is necessary to guide the development of an effective mentoring program in this speciality [17]. To forward a mentoring theory in Palliative Medicine in the midst of a lack of reports of mentoring programs in the extent literature requires 4 stages of consideration.

There must be clear parameters to focus this enquiry in the face of diverse mentoring practice. To set such parameters this paper focuses upon mentoring between senior clinicians and medical students and junior physicians. Acknowledging the goal specific features this paper confines its interest to mentoring in the undergraduate and postgraduate clinical and academic setting. Leadership, peer, youth, near-peer, family and patient mentoring are not considered. Addressing the context-specific nature of mentoring, only accounts of mentoring in systematic, literature and narrative reviews are considered. This allows clarity of the practices being reviewed and the exclusion of practices such as networking, supervision, preceptor ship and sponsorship that are often conflated with mentoring. Confining the focus of this paper upon reviews also tampers the variability and impact of mentoring's mentee- and mentor- dependent, speciality sensitive and healthcare specific nature alluded to by previous reviews of mentoring.

The second stage revolves around the assumptions made in adopting this approach. First, it is assumed that learning theories in medicine can be applied to the Palliative Medicine setting. This assumption draws upon prevailing editorials and commentaries upon mentoring in Palliative Medicine $[1,2,4,21,22]$. Second, context variability and differences in 
mentoring approaches, mentee profiles, mentor availability, clinical settings and prevailing organizational and healthcare systems in individual accounts of mentoring programs may be circumvented by drawing upon regnant literature, systematic and narrative reviews on mentoring. Third thematic analysis of mentoring practice in internal medicine will reveal consistent themes that can be applied to prevailing learning theories of mentoring to assess their viability.

The third stage involves the application of the specific 'evidence backed' learning theory of mentoring theory to a Palliative Medicine mentoring program. Appraisal of the program will aid the appropriate adaptation of the learning theory to better reflect mentoring in the Palliative Medicine setting.

The final stage for forwarding a learning theory of mentoring in Palliative Medicine is assessing the adapted learning theory of mentoring within various settings in Palliative Medicine such as hospice, hospital and home care settings and mentoring mentees from different specialities and different clinical backgrounds and experience along the tenets of Interprofessional Professional Education.

This paper involves the first two stages of forwarding of a learning theory of mentoring in Palliative Medicine.

\section{Characterizing mentoring practice in medicine}

A literature search using Pub Med, ERIC, Cochrane Database of Systematic Reviews, OVID and Science Direct databases identified literature reviews, systematic reviews and metaanalyses on the mentoring of medical undergraduates, residents and junior physicians by senior medical professionals in adult internal medicine between $1^{\text {st }}$ January 2000 and $31^{\text {st }}$ December 2015 revealed 6reviews of mentoring [Table 1].

There were six definitions of mentoring proffered by the reviews of mentoring in medicine identified in this study [Table 2]. These definitions form a central aspect of the thematic analysis of mentoring practice.

\section{Thematic analysis of definition of mentoring and the key findings of mentoring reviews}

Thematic analysis of the definition of mentoring and the key findings of mentoring reviews revealed a number of themes. We discuss each in turn. At its core, mentoring is focused on developing the mentee's potential. However the precise area of focus and mentoring approach employed is determined by the particular mentee's needs, personal, professional, social and academic situation and the objectives of the project and organization. This highlights both the context dependent [19] and the mentee- and mentor- dependent nature of mentoring $[6,7,12,15]$. We discuss each aspect in turn.

The context-dependent [19] feature of mentoring is underscored by differences in the overall objectives of mentoring in clinical, research and academic settings and between undergraduates and postgraduates [6,7,12,15,19-23]. Differences in mentoring in undergraduate and postgraduate settings also reveal a goal-dependent aspect to mentoring [6,7,12,15,19-23].In an undergraduate setting mentoring goals are often standardized and specified by the program[6,7,12,15,19].Postgraduate mentoring is guided by mentee-specific goals and/or clinical factors [6,7,12,15,19-23].

The impact of the personal characteristics, professional skills, academic abilities and social situations of mentees and mentors upon the goals, roles and responsibilities assumed by both parties underline the mentee- and mentor- dependent facets of mentoring [6,7,12,15,19-23].Mentoring processes have variously been described as dynamic and evolving as mentee's and/or mentor's academic, personal, professional and social situations change [6,7,12,15,19-23].

\section{Krishna's Mentoring Model}

Krishna suggests that mentoring is characterized by 8 key features. This includes

1. Mentor dependent factors

2. Mentee dependent factors

3. Organizational dependent factors

4. Goal specific features

5. Context sensitive features

6. The evolving nature of mentoring relationships

7. The quality of mentoring relationships

8. Mentoring environment

\section{Evaluating prevailing learning theories based on the thematic analysis}

An effective learning theory in mentoring must encapsulate the 8 key features highlighted by Krishna's Mentoring Model. We examine four dominant learning theories of mentoring in turn.

\section{Apprenticeship model}

Apprenticeship has long been seen as an integral part of physician training [25] and seesthe pairing of an experienced mentor and an inexperienced mentee to aid acquisition of 'tacit knowledge' and skill [27-29].An apprentice guided by the mentor begins at the periphery of the profession and progresses towards a greater clinical role through observing medical practitioners and gradually performing more tasks as they adapt and assimilate [27]. This training is focused on being a practitioner in the field rather than "learning about practice" [28].

The role of the mentor in role modelling skills, coaching through the provision of feedback, supporting learning through scaffolding, encouragement of mentees to articulate and explore their thoughts and reflect on their strengths and weaknesses; is critical to the apprenticeship $[27,28]$. This process is necessarily reflexive and dynamic to address changing contextual, goal, mentee- and mentor- dependent factors.

The success of the apprenticeship model, however, hinges upon an effective relationship between novice and mentor. 


\begin{tabular}{|c|c|c|c|}
\hline Title & Year & Authors & Definitions \\
\hline $\begin{array}{l}\text { Mentoring in Academic Medicine: A } \\
\text { Systematic Review [6] }\end{array}$ & 2006 & Sambunjak et al. & $\begin{array}{l}\text { 1. A dynamic, reciprocal relationship in a work environment between an } \\
\text { advanced career incumbent (mentor) and a beginner (mentee), aimed at } \\
\text { promoting the development of both. } \\
\text { 2. A partnership in personal and professional growth and development. }\end{array}$ \\
\hline $\begin{array}{l}\text { A Systematic Review of Qualitative Research } \\
\text { on the meaning and characteristics of } \\
\text { Mentoring in Academic Medicine [7] }\end{array}$ & 2010 & Sambunjak et al. & $\begin{array}{l}\text { 1. A complex relationship based on mutual interests, both professional and } \\
\text { personal } \\
\text { 2. The meaning of "mentorship" is context dependent; terms such as } \\
\text { "supervision" and "role-modelling" also are used interchangeably without } \\
\text { clear demarcation, all describing developmental interactions }\end{array}$ \\
\hline $\begin{array}{l}\text { Mentoring programs for medical students } \\
\text { - a review of the PubMed literature } 2000 \text { - } \\
2008 \text { [23] }\end{array}$ & 2010 & Frei et al. & $\begin{array}{l}\text { 1. A process whereby an experienced, highly regarded, empathetic person } \\
\text { (the mentor) guides another (usually younger) individual (the mentee) in the } \\
\text { development and re-examination of their own ideas, learning, and personal } \\
\text { and professional development. The mentor, who often (but not necessarily) } \\
\text { works in the same organization or field as the mentee, achieves this by } \\
\text { listening or talking in confidence to the mentee. } \\
\text { 2. An insightful process in which the mentor's wisdom is acquired and } \\
\text { modified as needed, as well as a process that is supportive and often } \\
\text { protective. The successful mentor-mentee relationship, therefore, requires } \\
\text { the active participation of both parties. The mentoring relationship can be } \\
\text { structured or loose. It can be a relatively short process or an ongoing one. } \\
\text { There can be breaks in the relationship, with its re-establishment at some } \\
\text { future time. The mentoring relationship is a dynamic one, evolving over } \\
\text { time, during which both parties continually define and redefine their roles. It } \\
\text { should be considered a process, not an end result, and the relationship must } \\
\text { remain non-competitive. } \\
\text { 3. Unlike coaching or counselling, mentoring is a cost-free career-promotion } \\
\text { strategy based on a personal relationship in a professional context. Whereas } \\
\text { a tutor, teacher/educator, coach, or supervisor mainly focuses on promoting } \\
\text { and supporting a junior's professional skills, a mentor is an active partner in } \\
\text { an ongoing relationship who helps a mentee to maximize his or her potential } \\
\text { and to reach personal and professional goals. } \\
\text { 4. A career mentor is someone who plays an active role in helping the student } \\
\text { in his/her professional and personal development. Mentoring also comprises } \\
\text { supporting a mentee in coping with stress and in establishing a satisfying } \\
\text { work-life balance. } \\
\text { 5. Mentoring is a relational process in which five phases can be } \\
\text { distinguished: information on career options, developing career plans, } \\
\text { focusing on career goals, the realization of career steps, and evaluation of } \\
\text { career advancement. }\end{array}$ \\
\hline $\begin{array}{l}\text { A Proposed Model for an Optimal Mentoring } \\
\text { Environment for Medical Residents: A } \\
\text { Literature Review [8] }\end{array}$ & 2010 & Davis et al. & $\begin{array}{l}\text { 1. A function of a relationship that (1) rests on a set of interactional } \\
\text { foundations (the fundamental elements of the mentor- protégérelationship } \\
\text { that inform their interactions) that allow a protégé to capitalize on his or her } \\
\text { mentor's strengths and (2) enables a protégéto engage in behaviours that } \\
\text { foster the development and growth that will yield a maximal outcome. }\end{array}$ \\
\hline $\begin{array}{l}\text { Mentoring Programs for Physicians in } \\
\text { Academic Medicine: A Systematic Review } \\
\text { [19] }\end{array}$ & 2013 & Kashiwagi et al. & $\begin{array}{l}\text { 1. Mentoring model or program, defined as a formal activity or series of } \\
\text { activities supporting the development and personal growth of physicians; } \\
\text { mentoring program for physicians out of training; mentors described as } \\
\text { medical professionals. } \\
\text { 2. The successful mentoring relationship in medicine develops when a } \\
\text { mentor with skills, knowledge, and experience provides advice, guidance, and } \\
\text { support to his or her mentee. These interactions foster characteristics and } \\
\text { qualities in mentees that enable a successful career trajectory }\end{array}$ \\
\hline $\begin{array}{l}\text { Mentoring Programs for Underrepresented } \\
\text { Minority Faculty in Academic Medical } \\
\text { Centers: A Systematic Review of the } \\
\text { Literature [24] }\end{array}$ & 2013 & Beech et al. & $\begin{array}{l}\text { 1. Although numerous definitions of mentoring exist in the professional } \\
\text { literature, traditionally it is a process through which a senior, experienced } \\
\text { faculty member (mentor) provides guidance and support for a junior or less } \\
\text { experienced colleague (mentee) } \\
\text { 2. A developmental partnership in which knowledge, experience, skills, } \\
\text { and information are shared between mentor(s) and mentee(s) to foster the } \\
\text { mentee's professional development and, often, also to enhance the mentor's } \\
\text { perspectives and knowledge. }\end{array}$ \\
\hline
\end{tabular}


Table 2: Definitions of Mentoring in Medicine

\begin{tabular}{|c|c|}
\hline Title & Key findings \\
\hline $\begin{array}{l}\text { Mentoring in Academic Medicine: A Systematic } \\
\text { Review [6] }\end{array}$ & $\begin{array}{l}\text { Mentoring is perceived as an important part of academic medicine, butthere is an absence of } \\
\text { experimental research to support this perception. Mentorship was an important influence on } \\
\text { personal development, career guidance, career choice, research productivity, including publication } \\
\text { and grant success. Women perceived that they had more difficulty finding mentors than colleagues } \\
\text { who are men. Practical recommendations on mentoring in medicine that are evidence-based } \\
\text { will require studies using more rigorousmethods, addressing contextual issues, and using cross- } \\
\text { disciplinary approaches. }\end{array}$ \\
\hline $\begin{array}{l}\text { A Systematic Review of Qualitative Research on } \\
\text { the meaning and characteristics of Mentoring } \\
\text { in Academic Medicine [7] }\end{array}$ & $\begin{array}{l}\text { Mentoring is a complex relationship based on mutual professional and personal interests. Mentees } \\
\text { should have the initiative in the development of the relationship, and mentors should be sincere, } \\
\text { listen actively and understand mentees' needs. Successful mentoring requires commitment } \\
\text { and interpersonal skills of the mentor and mentee, and a facilitating environment at academic } \\
\text { medicine's institutions. Mentorship is a uniquely encompassing relationship, characterised by high } \\
\text { levels of personal involvement and commitment. Relational and reciprocal outcomes like personal } \\
\text { growth, interdependence and connectedness are important and under investigated in mentoring in } \\
\text { academic medicine. }\end{array}$ \\
\hline $\begin{array}{l}\text { Mentoring programs for medical students - a } \\
\text { review of the Pub Med literature } 2000-2008 \\
\text { [23] }\end{array}$ & $\begin{array}{l}\text { Mentoring is an important career advancement tool for medical students. Mentorships must be } \\
\text { goal-oriented and rigorously evaluated in terms of the positive outcomes for mentees as well as for } \\
\text { mentors. A mentor should empower the mentee to reach his full potential, be a role model, build a } \\
\text { professional network and assist the mentee's personal development. A mentee should be initiated, } \\
\text { accept criticism, and be able to assess the benefits of the mentoring relationship. More mentoring } \\
\text { programs should be developed, but would need to be assessed and documented based on evidence } \\
\text { of their value in terms of helping the mentees and mentors. Medical schools could then be monitored } \\
\text { with respect to the provision of mentorships as a tenet of medical education }\end{array}$ \\
\hline $\begin{array}{l}\text { A Proposed Model for an Optimal Mentoring } \\
\text { Environment for Medical Residents: A } \\
\text { Literature Review [8] }\end{array}$ & $\begin{array}{l}\text { This model incorporates six foundations all mentoring relationships should have, namely emotional } \\
\text { safety, support, mentee-centeredness, informality, responsiveness and respect. Encompassing all } \\
\text { six foundations would allow mentees to develop key behaviours like exercising independence, } \\
\text { reflecting, extrapolating and synthesizing. The empowerment of mentees will help them reach their } \\
\text { full potential as physicians. }\end{array}$ \\
\hline $\begin{array}{l}\text { Mentoring Programs for Physicians in } \\
\text { Academic Medicine: A Systematic Review [19] }\end{array}$ & $\begin{array}{l}\text { There are seven potential components in a mentoring program: Mentor preparation, planning } \\
\text { committees, mentor-mentee contracts, mentor-mentee pairing, mentoring activities, formal } \\
\text { curricula and program finding. Protected time was valued by both mentors and mentees, and } \\
\text { written agreements encouraged accountability to the mentoring relationship. Limited resources } \\
\text { were a major barrier to the quality of mentoring relationships. }\end{array}$ \\
\hline $\begin{array}{l}\text { Mentoring Programs for Underrepresented } \\
\text { Minority Faculty in Academic Medical Centres: } \\
\text { A Systematic Review of the Literature [24] }\end{array}$ & $\begin{array}{l}\text { Mentoring is an important part of academic } \\
\text { Mentoring is an important part of academic medicine, but few publications documented mentoring } \\
\text { programs. Barriers to mentoring relationships are identified, including time-restricted funding, } \\
\text { inadequate evaluation and feedback, significant time commitments required from mentors, and } \\
\text { institutional challenges. Lack of funds was also prominent as programs had minimal institutional } \\
\text { support. }\end{array}$ \\
\hline
\end{tabular}

Mentor training and the mentor's ability to mentor and facilitate learning at each stage of the apprenticeship is critical and often unconsidered [27-32]. Neither is the mentee's attitude, skills and willingness to be guided [27-32]. Implicit in the apprenticeship model are assumptions that mentees are motivated and see the value of the apprenticeship process and its relevance to their future careers [33]. In addition, apprenticeship assumes that mentees have some basic skills and experience to build upon particularly within the context of Palliative Medicine. This limits the viability of apprenticeship amongst undergraduates and highlights the implied concepts most commonly associated with adult learning theories.

\section{The multi-theories model}

Knowles'sAdult learning theory [34] pivots upon encompasses five critical assumptions

1. Adult learners tend to be self-directed

2. Adult learners build upon their experiences

3. The adult learners readiness to learn is related to their social roles

4. The adult learners orientation to learning shifts from subject-centred to performance-centred

5. The motivation to learn in adult mentees is intrinsic rather than extrinsic[35] 
Within the Palliative Care setting and particularly within the context of undergraduate training and early postgraduate training, some of Knowles's principles struggle to gain traction. To begin learners are extrinsically motivated to complete compulsory postings. Undergraduates frequently have little exposure to an interdisciplinary team working and end of life care to build upon whilst a limited understanding of the subject matter and the various aspects of importance restricts their ability to be self-directed learners. Similarly, not all learners are 'ideal' adult learners [36]. Wu et al [37] and Wahab et al [38] argue that the mentee's and mentor's character and the learning context have significant bearing upon learning. The individualized and context-dependent nature of mentoring process and impact of both the quality and the evolving nature of the relationships further suggest that application of the adult learning theory to the Palliative Care setting requires adaptation.

Adapting Taylor and Hamdy [39]multi-theories model which proffers an evolution on adult learning theories offers a potential avenue to an implementation of the adult learning theory [3941]. Furthermore Taylor and Hamdy [39] multi-theories model places significant importance upon a key element of mentoring - the mentor-mentee relationship [39-41]. The multi-theories model consists of five stages, each of which confers differing responsibilities to the mentee and the mentor reflecting the evolving nature of mentoring relationships. In the dissonance phase, gaps are identified in the mentee's knowledge. The mentor's role in this phase involves assessing the mentee's motivation, learning styles and stage of development in order to formulate a mentoring plan and provide the mentee with the necessary resources they would require to develop.

The refinement phase is characterised by the formation of new concepts brought about by the addition of new data and experiences to existing knowledge and understanding. This is achieved through brainstorming for possible solutions to different problems, active participation and completion of tasks, and refining these experiences and data into concepts.

In the organisation phase, mentees restructure their existing knowledge pool through the process of validating hypotheses of the new knowledge. The feedback and consolidation phases allow the mentee to reflect and validate any new information, acknowledging the increase in their knowledge base as well as the learning process.

The flexibility of this model [39] allows its application to a wide range of mentor-mentee relationships [42] and settings [43]. It is likely that given the evolving nature of mentoring practice and different goals of mentoring within each stage of the mentoring process, the five stages of mentoring may occur concurrently.

\section{Source of Variance theory}

The source of Variance theory of mentoring derived from observations of mentoring in psychology by O'Neil and Wrights man [40] also focuses on the quality of mentoring relationships. The Source of Variance theory of mentoring is influenced by
4 domains of mentoring. The factors influencing mentoring relationships include the role of mentor and mentee, their personalities, situational variables and diversity variables. The parameters influencing mentoring relationships pertain to the degree of mutuality, breadth and depth of the relationship, congruence of mentor and mentee needs and their sensitivity to diversity. The correlates influencing mentoring relationships refers aspects of mentoring dynamics and encompasses interpersonal respect, professionalism-collegiality, role fulfilment, power, control and competition. The six "critical activities that define the working relationship" [40] include making the crucial entry decision, building mutual trust, taking risks, teaching skills, learning professional standard, and dissolving or changing of the relationship.

Whilst these domains do complement Taylor and Hamdy's multi-theories model[39]and attempt to shed more light on the mentoring relationship, there is little if any data to support either model.

\section{Multiple Mentors Theory}

Given the holistic, multiprofessional and longitudinal nature of Palliative Care, Periyakoil [2] and Jackson \&Arnold [4] suggest a similar approach in mentoring in Palliative Care. This approach echoes Higgins and Kram's [46] exploration of the idea of a mentee having multiple mentors. Higgins and Kram suggest that four factors affected a mentee's developmental network and contribute to the efficacy of the mentoring relationships: the network itself, the developmental relationships in the network, the diversity of the network and the strength of the relationships in the network. The developmental network refers to people in whom the mentee may have an active interest in seeking career advice and support of their professional and personal goals. The different types of relationships present in the network such as "mentor, sponsor, coach and peer" provide differing amounts of career and psychosocial support. Diversity is defined as the number of different social systems the relationships stem from, and the extent to which the people in the network are connected to one another. Finally, the strength of the relationship refers to the level of emotional affect, reciprocity and frequency of communication [47].

Many of the assumptions that this theory is built upon remain unproven and like the theories discussed previously remain largely theoretical. Furthermore, the multiple mentors theory like the other theories discussed do not consider cultural, organizational nor clinical contexts [48].

\section{Discussion}

It is evident that a mentoring theory in Palliative Care must necessarily encapsulate Krishna's Mentoring Model. Thus far it would appear that Taylor and Hamdy [39] multi-theories model appears to best capture these considerations albeit with the inclusion of the multiple mentor theory to capture the multi professional and multidimensional nature of Palliative Care. The 
apprenticeship model also proffers a practical consideration about clinical practice in palliative Care and indeed clinical care as a whole. Both the apprenticeship model and the multiple mentor theory also make tacit references to the adult learning theory that Taylor and Hamdy then build upon whilst the Source of Variance theory underlines the central importance of mentoring relationships in such practice.

Lapses in consideration of the evolving nature of mentoring and the presence of changing and often multiple short and medium term goals within the overall objective of the mentoring process highlight the need for further 'tweaking' of the theory. Cultural and organizational considerations impacting the mentoring process and context in which mentoring relationships occur need to be better considered in any future mentoring theory. Critically efforts must be made to integrate Palliative Care's multiprofessional educational, training and practice approach. Such an approach must encapsulate the principles of Interprofessional Education [49] and sensitivity to the need for multiple mentors often concurrently at various stages of the mentee's development.

Finally, a significant assumption that has underpinned this discussion also requires closer scrutiny, the viability of extrapolating mentoring data from a medical setting to allied health.

\section{Future research}

The field of mentoring research is rich with potential and one key area in need of further study is the dynamics of mentoring relationships, the quality of the mentoring relationship and how they evolve from the perspective of mentees and mentors.

Effective research methods and longitudinal studies that consider how mentoring relationships form, the impact of organizational factors and the mentoring environment upon mentoring interactions and personal ties are also required.

The context sensitive nature of mentoring demands that mentoring in nursing, medical social work, physiotherapy, occupational therapy and chaplaincy be carried out. Comparisons between the various approaches would allow common themes to be identified that will lead to the implementation of a Palliative Care specific mentoring approach that can be assessed for its efficacy. The lessons learnt will fuel the development of a mentoring theory in Palliative Care

\section{Conclusion}

The goal of this paper was to delineate a data-driven learning theory of mentoring between senior clinician and an undergraduate or a junior physician within the Palliative Care context that could be used to inform the design of mentoring programs in this specialty. Dissonance between prevailing theoretical conceptions of mentoring and regnant mentoring data has made forwarding such a mentoring theory difficult.

However Krishna's Mentoring Model highlighting the key facets that must be encapsulated in any potential theory of mentoring and adaptation of Taylor and Hamdy's [37] approach to forwarding a data driven learning theory suggests that an effective platform for a future mentoring theory could still be possible so long as robust context specific studies are developed to guide this process.

\section{Disclosure statement}

\section{Acknowledgments}

The authors would like to dedicate this paper to Dr S Radha Krishna and Dr Deborah Watkinson whose advice and ideas were integral to the success of this study and who sadly passed away during the writing of this paper.

\section{References}

1. Arnold RM. Mentoring the next generation: a critical task for palliative medicine. Journal of palliative medicine. 2005;8(4):696-698. doi:10.1089/jpm.2005.8.696.

2. Periyakoil VS. Declaration of interdependence: The need for mosaic mentoring in palliative care. Journal of palliative medicine. 2007;10(5):1048-1049. doi:10.1089/jpm.2006.9911.

3. Tran K, Tran GT, Fuller R. West Yorkshire Mentor Scheme: teaching and development. The Clinical Teacher Clin Teach. 2014;11(1):48-52. doi:10.1111/tct.12058.

4. Jackson V, Arnold RM. A Model of Mosaic Mentoring. Journal of palliative medicine. 2010;13(11):1371. doi: 10.1089/jpm.2010.9764.

5. Connor M, Bynoe A, Redfern N, Pokora J, Clarke J. Developing senior doctors as mentors: a form of continuing professional development. Report of an initiative to develop a network of senior doctors as mentors: 1994-99. Medical Education-Oxford. 2000;34(9):747-753. doi:10.1046/j.1365-2923.2000.00630.x.

6. Sambunjak D, Straus SE, Marušić A. Mentoring in academic medicine: a systematic review. Jama. 2006;296(9):1103-1115. doi: 10.1001/ jama.296.9.1103.

7. Sambunjak D, Straus SE, Marusic A. A systematic review of qualitative research on the meaning and characteristics of mentoring in academic medicine. Journal of general internal medicine. 2010;25(1):72-78. doi: 10.1007/s11606-009-1165-8.

8. Davis OC, Nakamura J. A proposed model for an optimal mentoring environment for medical residents: A literature review. Academic Medicine. 2010;85(6):1060-1066. doi:10.1097/ ACM.0b013e3181dc4aab.

9. Zuzuarregui JRP, Hohler AD. Comprehensive Opportunities for Research and Teaching Experience (CORTEX): A mentorship program. Neurology. 2015;84(23):2372-2376. doi:10.1212/ wnl.0000000000001663.

10. Bourgeois JA, Hategan A, Azzam A. Competency-based medical education and scholarship: Creating an active academic culture during residency. Perspect Med Educ Perspectives on Medical Education. 2015;4(5):254-258. doi:10.1007/s40037-015-0218-4.

11. Riley M, Skye E, Reed BD. Mentorship in an academic department of family medicine. Fam Med. 2014;46(10):792-796. PMID: 25646831.

12. Steiner JF, Curtis P, Lanphear BP, Vu KO, Main DS. Assessing the role of influential mentors in the research development of primary care fellows. Acad Med. 2004;79(9):865-872. PMID: 15326013.

13. Mark S, Link H, Morahan PS, Pololi L, Reznik V, Tropez-Sims S. Innovative Mentoring Programs to Promote Gender Equity in Academic Medicine. Acad Med. 2001;76(1):39-42. doi:10.1097/00001888200101000-00011. 
14.Afghani B, Santos R, Angulo M, Muratori W. A Novel Enrichment Program Using Cascading Mentorship to Increase Diversity in the Health Care Professions. Acad Med. 2013;88(9):1232-1238. doi:10.1097/acm.0b013e31829ed47e.

15. Stamm M, Buddeberg-Fischer B. The impact of mentoring during postgraduate training on doctors' career success. Med Educ. 2011;45(5):488-496. doi:10.1111/j.1365-2923.2010.03857.

16. Burns LJ, Clayton CP, George JN, Mitchell BS, Gitlin SD. The Effect of an Intense Mentoring Program on Junior Investigators' Preparation for a Patient-Oriented Clinical Research Career. Acad Med. 2015;90(8):1061-1066. doi:10.1097/acm.0000000000000742.

17. Areephanthu CJ, Bole R, Stratton T, Kelly TH, Starnes CP, Sawaya BP. Impact of Professional Student Mentored Research Fellowship on Medical Education and Academic Medicine Career Path. Clinical and Translational Science. 2015;8(5):479-483. doi:10.1111/cts.12289.

18. Dehon E, Cruse M, Dawson B, Jackson-Williams L. Mentoring During Medical School and Match Outcome Among Emergency Medicine Residents. Western Journal of Emergency Medicine WestJEM. 2015;16(6):927-930. doi:10.5811/westjem.2015.9.27010.

19. Kashiwagi DT, Varkey P, Cook DA. Mentoring Programs for Physicians in Academic Medicine: A Systematic Review. Acad Med. 2013;88(7):1029-1037. doi:10.1097/ACM.0b013e318294f368.

20. Buddeberg-Fischer B, Herta KD. Formal mentoring programmes for medicalstudentsanddoctors-areview of the Medlineliterature.Medical Teacher. 2006;28(3):248-257. doi:10.1080/01421590500313043.

21. Carey EC, Weissman DE. Understanding and finding mentorship: A review for junior faculty. Journal of Palliative Medicine. 2010;13(11):1373-1379. doi:10.1089/jpm.2010.0091.

22. Case AA, Orrange SM, Weissman DE. Palliative medicine physician education in the United States: a historical review. Journal of palliative medicine. 2013;16(3):230-236. doi:10.1089/jpm.2012.0436.

23. Frei E, Stamm M, Buddeberg-Fischer B. Mentoring programs for medical students-a review of the PubMed literature 2000-2008. BMC medical education. 2010;10(1):32. doi:10.1186/1472-6920-10-32.

24. Beech BM, Calles-Escandon J, Hairston KG, Langdon MSE, LathamSadler BA, Bell RA. Mentoring programs for underrepresented minority faculty in academic medical centers: a systematic review of the literature. Academic medicine: journal of the Association of American Medical Colleges. 2013;88(4). doi: 10.1097/ACM.0b013e31828589e3.

25. Siddiqui S. Of mentors, apprenticeship, and role models: a lesson to relearn? Medical education online. 2014;19. doi:10.3402/meo. v19.25428.

26. Dennen VP. Cognitive Apprenticeship in Educational Practice: Research on Scaffolding, Modelling, Mentoring, and Coaching as Instructional Strategies. In: Jonassen DH, editor. Handbook of research on education communications and technology. $2^{\text {nd }}$ ed. Mahwah, NJ, US: Lawrence Erlbaum Associates Publishers; 2004. p. 1210

27. Stalmeijer RE, Dolmans DH, Wolfhagen IH, Scherpbier AJ. Cognitive apprenticeship in clinical practice: can it stimulate learning in the opinion of students? Advances in Health Sciences Education 2009;14(4):535-546. doi:10.1007/s10459-008-9136-0.

28. Collins A, Brown JS, Newman SE. Cognitive apprenticeship. Thinking: The Journal of Philosophy for Children. 1988;8(1):2-10.

29. Dornan T, Hadfield J, Brown M, Boshuizen H, Scherpbier A How can medical students learn in a self-directed way in the clinical environment? Design-based research. Medical education. 2005;39(4):356-364. doi: 10.1111/j.1365-2929.2005.02112.x.

30. Halpern SD, Detsky AS. Graded autonomy in medical educationmanaging things that go bump in the night. New England Journal of Medicine. 2014;370(12):1086-1089. doi:10.1056/NEJMp1315408.
31. Sheehan D, Bagg W, de Beer W, Child S, Hazell W, Rudland J, et al. The good apprentice in medical education. The New Zealand Medical Journal (Online). 2010;123(1308). PMID:20201158.

32.0'Connell HP. Spicing up Medical Education. Student BMJ. 2009;17:b2390.

33. Dills CR, Romiszowski AJ. Instructional development paradigms: Educational Technology; 1997.

34. Knowles MS. The modern practice of adult education: From Pedagogy to Andragogy (revised and updated). 1980. Cambridge Adult Education, United Kingdom

35. Knowles MS, et al. Andragogy in action: Applying modern principles of adult learning. 1984. Jossey-Bass, California.

36. Hanson, A. The search for separate theories of adult learning: does anyone really need andragogy? In Edwards, R., Hanson, A., and Raggatt, P., editors. Boundaries of Adult Learning. Adult Learners, Education and Training, Vol. 1 (p. 107) London: Routledge

37. Wu JT, Wahab MT, Ikbal MFM, Wesley LTW, Kanesvaran R, et al. Toward an Interprofessional Mentoring Program in Palliative Care - A Review of Undergraduate and Postgraduate Mentoring in Medicine, Nursing, Surgery and Social Work. 2016. J Palliat Care Med 6: 292. doi:10.4172/2165-7386.1000292

38. Wahab MT, Ikbal MFM, Wu JT, Wesley LTW, Kanesvaran R, et al. Creating Effective Interprofessional Mentoring Relationships in Palliative Care- Lessons from Medicine, Nursing, Surgery and Social Work. Journal of Palliative Care \& Medicine. 2016. doi: 10.4172/21657386.1000290

39. Taylor DC, Hamdy H. Adult learning theories: Implications for learning and teaching in medical education: AMEE Guide No. 83 Medical Teacher. 2013;35(11):e1561-1572. Doi:10.3109/014215 9X.2013.828153

40. O'Neil JM, Wrightsman LS. The mentoring relationship in psychology training programs. In: Walfish S, Hess AK, editors. Succeeding in graduate school: The career guide for psychology students. Mahwah, NJ, US: Lawrence Erlbaum Associates Publishers; 2001. p.111-127

41. Ingham H, Luft J. The Johari window a graphic model of interpersonal awareness. Western training laboratory in group development. 1955.

42. Knowles M. The adult learner: a neglected species. 1973.

43. Hawkins A, Jones K, Stanton A. A mentorship programme for finalyear students. The clinical teacher. 2014;11(5):345-349. doi:10.1111/ tct.12149

44. Mirghani HM, Ezimokhai M, Shaban S, van Berkel HJ. Superficial and deep learning approaches among medical students in an interdisciplinary integrated curriculum. Education for Health. 2014;27(1):10. doi:10.4103/1357-6283.134293

45. Brass DJ. A social network perspective on human resources management. Networks in the knowledge economy. 2003:283-323.

46. Higgins MC, Kram KE. Reconceptualizing mentoring at work: A developmental network perspective. Academy of Management Review. 2001;26(2):264-288.

47. Granovetter MS. The strength of weak ties. American journal of sociology. 1973:1360-1380.

48. Durning SJ, Artino AR. Situativity theory: A perspective on how participants and the environment can interact: AMEE Guide no. 52. Medical teacher. 2011;33(3):188-199. Doi:10.3109/014215 9X.2011.550965

49. Sullivan M, Kiovsky RD, Mason DJ, Hill CD, Dukes C. Interprofessional collaboration and education. AJN The American Journal of Nursing. 2015;115(3):47-54. doi:10.1097/01.NAJ.0000461822.40440.58 